\title{
26339 - COMPARISON OF INSERTION TIMES BETWEEN A NEW INDICATOR-GUIDED (IG) AND CONVENTIONAL WIRE-GUIDED (WG) CRICOTHYROIDOTOMY
}

\author{
Nicole Assmann FRCA, David T Wong, MD; Eduardo Morales, MD; \\ Toronto Western Hospital, Toronto, ON, Canada
}

INTRODUCTION: Percutaneous cricothyroidotomy is a life saving procedure in cannotintubate cannot-ventilate situations. Recently, a new indicated-guided cricothyroidotomy device was developed. The objective of this study was to assess the insertion times of 5 consecutive attempts of Seldinger wired-guided (WG) vs indicated-guided (IG) technique on mannequins.

METHODS: After approval by the institutional REB, half the subjects were randomized to perform 5 WG cricothyroidotomy attempts followed by $5 \mathrm{IG}$ attempts and the other half proceeded in reverse order. Subjects were shown demonstration videos prior to attempts. A cricothyroidotomy mannequin (LF1082U, Nasco Inc) was used. For the WG technique, a 5mm ID cuffed percutaneous dilational cricothyroidotomy kit (Cook Inc.) was utilized. For the IG technique, a kit (Portex Inc.) consisting of an integrated cuffed $6 \mathrm{~mm}$ ID cricothyroidotomy tube, obturator, and a core needle with an indicator was used. After a scalpel skin incision, the cricothyroidotomy was inserted. A red indicator in the needle hub became visible when the spring-loaded retractable blunt needle tip made contact with the cricothyroidotomy membrane. The indicator disappeared upon needle entry into the airway lumen and re-appeared when the needle touched the posterior wall of the airway. The cricothyroidotomy was then angled caudally until the indicator became invisible. The cricothyroidotomy was advanced $1-2 \mathrm{~cm}$ and the needle removed. Then, the cricothyroidotomy tube was advanced over the obturator into the airway. For both devices, the times from skin palpation to ventilation of airway were recorded for 5 consecutive attempts. The insertion times of the 5 attempts between the two techniques were compared using paired t-tests. $\mathrm{P}<0.05$ was considered statistically significant. RESULTS: 64 anesthesiologists participated. $42 \%$ were attendings, $34 \%$ fellows and $23 \%$ residents. Overall, $93 \%$ of WG and $95 \%$ of IG attempts were successfully completed (non-significant). The insertion times for the first to fifth attempts of both techniques are shown in the Table. The IG times were shorter than WG times at all five attempts $(\mathrm{p}<0.01)$. The insertion times and demographics were similar for the groups randomized to perform WG or IG first.

DISCUSSIONS: The overall success rates for insertion were similar with the two cricothyroidotomy techniques on mannequins. However, the insertion times were significantly shorter in all 5 attempts using the IG compared to the WG technique. 


\begin{tabular}{|c|c|c|c|c|}
\hline $\begin{array}{c}\text { Attempt } \\
\text { mumber }\end{array}$ & $\begin{array}{c}\text { Wire-Guided } \\
\text { (Mean }+ \text { SD) sec }\end{array}$ & $\begin{array}{c}\text { Indicator-Guided } \\
\text { (Mean } \pm \text { SD) sec }\end{array}$ & $\begin{array}{c}95 \% \text { CI of } \\
\text { difference, sec }\end{array}$ & P value \\
\hline 1 & $52.4 \pm 13.9$ & $45.2 \pm 15.1$ & $2.1-12.3$ & $\mathrm{P}=0.006$ \\
\hline 2 & $47.1 \pm 11.7$ & $35.9 \pm 16.3$ & $6.9-15.7$ & $\mathrm{P}<0.001$ \\
\hline 3 & $40.0 \pm 9.9$ & $30.6 \pm 12.4$ & $6.1-12.7$ & $\mathrm{P}<0.001$ \\
\hline 4 & $37.5 \pm 10.2$ & $27.1 \pm 10.2$ & $7.2-13.5$ & $\mathrm{P}<0.001$ \\
\hline 5 & $35.9 \pm 8.5$ & $25.9 \pm 11.8$ & $6.6-13.4$ & $\mathrm{P}<0.001$ \\
\hline
\end{tabular}

